\title{
Anatomia óssea do cíngulo pélvico, da coxa e da perna do tamanduá bandeira Myrmecophaga tridactyla (Myrmecophagidae: Pilosa)
}

\author{
Priscilla Rosa Queiroz Ribeiro * \\ André Luiz Quagliatto Santos \\ Rogério Rodrigues de Souza \\ Saulo Gonçalves Pereira \\ Daniela Cristina Silva Borges \\ Lucas de Assis Ribeiro \\ Tharlianne Alici Martins de Souza \\ Laboratório de Ensino e Pesquisa em Animais Silvestres \\ Universidade Federal de Uberlândia, Uberlândia - MG, Brasil \\ * Autor para correspondência \\ priscillarqr@yahoo.com.br \\ Rua Waldomira Rezende, 290, apto 103, CEP 38.408-078, Uberlândia-MG, Brasil
}

Submetido em 25/11/2012

Aceito para publicação em 02/09/2013

\section{Resumo}

O tamanduá bandeira (Myrmecophaga tridactyla) é a maior espécie de tamanduá do mundo. É um animal de hábitos terrestres, entretanto, apresenta alguma habilidade para escalar árvores e cupinzeiros altos. As estruturas esqueléticas duras são de importância vital, pois unem e protegem os órgãos moles, ajudam a sustentar o corpo, conferem forma e envolvem-se no movimento. O esqueleto apendicular é parte importante do aparelho locomotor, cujas informações anatômicas em espécies selvagens são escassas, tornando difícil a interpretação de dados relativos a esses ossos. Este artigo teve por objetivo descrever o esqueleto do cíngulo pélvico, coxa e perna do tamanduá bandeira. Foram utilizados dois espécimes de Myrmecophaga tridactyla Linnaeus (1758), fixados em solução aquosa de formaldeído a 3,7\%. Inicialmente, os membros foram desarticulados e foi realizada a retirada da pele, vísceras e musculatura associada aos ossos do cíngulo pélvico, coxa e perna dos espécimes. Em seguida, eles foram macerados em água fervente e, posteriormente, colocados em solução de peróxido de hidrogênio. Depois de limpos e secos, os ossos foram identificados e descritos. O esqueleto do cíngulo pélvico do tamanduá bandeira é constituído pelo osso do quadril, formado pelos ossos ílio, púbis e ísquio; a coxa é constituída pelo osso fêmur; e a perna pelos ossos tíbia e fíbula. Na região da articulação do joelho encontra-se a patela, um osso sesamóide relativamente pequeno, considerando-se o grande porte desse animal. O tamanduá bandeira possui características osteológicas do cíngulo pélvico, da coxa e da perna semelhantes àquelas dos carnívoros domésticos, entretanto, algumas diferenças morfológicas são evidenciadas, o que pode refletir as diferenças dos padrões locomotores.

Palavras-chave: Locomoção; Osteologia; Xenarthras 


\section{Abstract}

Bone anatomy of the pelvic girdle, the thigh and the leg of Myrmecophaga tridactyla (Myrmecophagidae: Pilosa). The giant anteater (Myrmecophaga tridactyla) is the largest anteater species in the world. It is an animal of terrestrial habits, however, it has some ability to climb tall trees and termite mounds. The hard skeletal structures are of crucial importance, since they join and protect the soft organs and help support the body, shape, and get involved in movement. The appendicular skeleton is an important part of the locomotor apparatus, whose anatomical information in wild species is scarce, making it difficult to interpret data on these bones. This paper aims to describe the pelvic girdle, the thigh, and the leg skeleton in the giant anteater. We used two specimens of Myrmecophaga tridactyla Linnaeus (1758), fixed in a 3.7\% aqueous formaldehyde solution. At first, the limbs were disjointed and we removed the skin, viscera, and muscles associated to the bones of the pelvic girdle, the thigh, and the leg in the specimens. Then, they were macerated in boiling water, and, subsequently, placed in a hydrogen peroxide solution. Once clean and dry, the bones were identified and described. The pelvic girdle skeleton in the giant anteater consists of the hip bone, formed by the ilium, pubis, and ischium bones; the thigh consists of the femur bone, and the leg consists of the tibia and fibula bones. In the knee joint region there is the patella, a relatively small sesamoid bone, considering the large size of this animal. The giant anteater have osteological features of the pelvic girdle, the thigh, and the leg similar to those in domestic carnivores, however, some morphological differences are made evident, something which may reflect differences in locomotor patterns.

Key words: Locomotion; Osteology; Xenarthras

\section{Introdução}

Segundo Collevatti et al. (2007), o tamanduá bandeira é a maior espécie de tamanduá do mundo e está amplamente distribuído na América Central e do Sul, apesar de sua ampla abrangência ter sido extinta em muitas áreas da sua original distribuição. Medri e Mourão (2005) afirmam que a distribuição dos tamanduás ocorre a partir do sul da Guatemala até o norte da Argentina, abarcando uma variedade de habitats nas altitudes baixas e podendo atingir altas densidades, onde seu alimento, que consiste principalmente de formigas e cupins, é abundante.

Maior representante da família Myrmecophagidae, o tamanduá bandeira possui pelagem densa e de coloração cinza escura a preta e cauda comprida com pelos grossos e longos. É uma espécie de hábitos terrestres, cuja alimentação é constituída principalmente por formigas e cupins, embora apresente alguma habilidade para escalar árvores e cupinzeiros altos (MEDRI et al., 2011).

Fisiologicamente o esqueleto é algumas vezes considerado relativamente inerte. Entretanto, de um ponto de vista funcional é de importância fundamental. Filogeneticamente o esqueleto procede de tecidos conectivos e ontogenicamente se desenvolve a partir deles. As estruturas esqueléticas duras são de importância vital, pois unem e protegem os órgãos moles, permitem sustentar o corpo, dão forma e se envolvem no movimento (MARTÍNEZ, 2007).

Silveira e Oliveira (2008) afirmam que a utilização de esqueletos auxilia nas atividades científicas e didáticas, por fornecer informações seguras sobre as adaptações específicas dos vertebrados, como sustentação, postura e modo de locomoção e que há grande importância no uso dos esqueletos como ferramentas fundamentais para pesquisa científica na identificação de caracteres para análises anatômicas.

O esqueleto apendicular se refere ao conjunto de elementos ósseos que sobressaem a ambos os lados do esqueleto axial, cranial e caudalmente (MARTÍNEZ, 2007). É parte do aparelho locomotor e compreende os membros torácicos e pélvicos (GETTY, 1986a). Oliveira et al. (2009) destacam que em espécies selvagens informações anatômicas sobre o esqueleto apendicular são escassas, tornando difícil a interpretação de dados relativos a esses ossos.

Sendo assim, considerando a importância do conhecimento osteológico dos membros em diferentes espécies, o presente artigo teve por objetivo descrever o esqueleto do cíngulo pélvico, coxa e perna do tamanduá bandeira. 


\section{Material e Métodos}

O presente estudo foi aprovado pela Comissão de Ética no Uso de Animais da Universidade Federal de Uberlândia (Protocolo no 039/11) e está de acordo com a Instrução Normativa 154/2007 do IBAMA.

Foram utilizados dois espécimes de Myrmecophaga tridactyla Linnaeus (1758) fixados em solução aquosa de formaldeído a 3,7\%, pertencentes aos acervos didáticocientíficos do Laboratório de Ensino e Pesquisa em Animais Silvestres (LAPAS) da Universidade Federal de Uberlândia (UFU) e do Laboratório de Anatomia da Universidade Federal de Goiás, Campus Catalão (UFG).

Inicialmente os membros pélvicos foram desarticulados e foi realizada a retirada da pele, tecido adiposo, fáscias, ligamentos, vasos, nervos e musculatura associada aos ossos do cíngulo pélvico, coxa e perna dos espécimes avaliados. Em seguida os mesmos foram macerados em água fervente por $12 \mathrm{~h}$, mantidos submersos em água por $48 \mathrm{~h}$, lavados em água corrente e posteriormente colocados por $12 \mathrm{~h}$ em solução de peróxido de hidrogênio comercial a 130 volumes diluídos em água em uma parte para quarenta, conforme proposto por Rodrigues (2005).
Depois de limpos e secos, os ossos foram identificados, fotodocumentados, descritos e nomeados segundo as designações anatômicas, obedecendo a Nomina Anatômica Veterinária (INTERNATIONAL COMMITTEE ON VETERINARY GROSS ANATOMICAL NOMENCLATURE, 2012).

\section{Resultados}

O esqueleto do cíngulo pélvico do tamanduá bandeira consistiu do osso do quadril, formado por três ossos, o ílio, ísquio e púbis (Figura 1). Nos animais estudados, por se tratarem de espécimes adultos, esses ossos eram fundidos, formando uma peça única de conexão entre o membro pélvico, ventralmente, e a parte sacral da coluna vertebral, dorsalmente.

O ílio era o maior e mais cranial dos três ossos do quadril do tamanduá bandeira, era um osso plano, de forma irregular e apresentou duas faces e um corpo. A parte mais larga desse osso era a asa do ílio, que apresentou as faces glútea e sacropélvica. A face glútea era côncava e voltada dorsolateralmente, a sacropélvica era ligeiramente convexa e possuía uma área rugosa para a articulação com o osso sacro. A asa do ílio terminou em

FIGURA 1: Fotomacrografia do osso do quadril do tamanduá bandeira (Myrmecophaga tridactyla). (A), vista ventral; (B), vista dorsal. Ac, acetábulo; AI, asa do ílio; AR, área rugosa articular com o sacro; CI; crista ilíaca; Ci, corpo do ílio; Ci”, corpo do ísquio; CP, corpo do púbis; FA, fossa acetabular; FG, face glútea; FO, forame obturado; FS, face sacropélvica; IA, incisura do acetábulo; II, incisura isquiática; RC, ramo cranial do púbis; Rc, ramo caudal do púbis; RI, ramo do ísquio; TC, tuberosidade coxal; TI, tuberosidade isquiática; TP, tubérculo púbico ventral; TS, tuberosidade sacral.
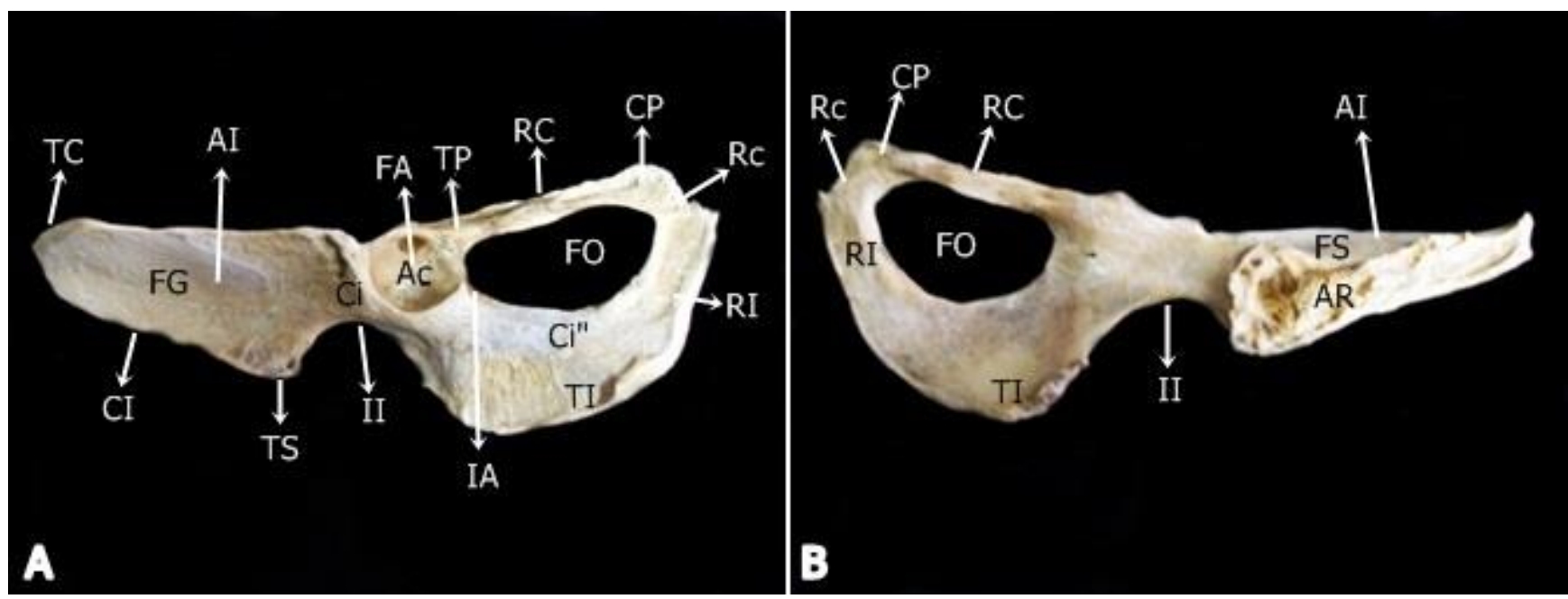
duas extremidades angulares, denominadas tuberosidade sacral, situada medialmente; e tuberosidade coxal, lateralmente. Entre as duas tuberosidades encontrou-se a crista ilíaca. O corpo do ílio era estreito e terminou fundindo-se ao púbis e ísquio, no acetábulo (Figura 1).

O púbis era o menor dos três ossos do quadril do tamanduá bandeira, constituído por um ramo cranial, um ramo caudal e um corpo. O ramo cranial dirigiu-se para fora para terminar no acetábulo e em sua extremidade lateral encontrou-se o tubérculo púbico ventral, enquanto o ramo caudal era menor e mais delgado e continuou-se com o ísquio, o corpo do púbis era a área de união entre os dois ramos. Os dois púbis uniam-se no plano mediano, formando a parte cranial da sínfise pélvica (Figura 1).

O ísquio do tamanduá bandeira constituiu a porção caudal da pelve e apresentou ramo, corpo, tuberosidade, incisura e espinha. $\mathrm{O}$ ramo era a porção mais medial do osso e unia-se com o antímero oposto para formar a parte caudal da sínfise pélvica. O corpo do ísquio estava unido sem limites nítidos com o ramo e se estendeu até o acetábulo. A tuberosidade isquiática era uma estrutura óssea bastante extensa. A incisura isquiática se continuou com a tuberosidade sacral caudalmente (Figura 1).
O acetábulo era a cavidade que alojava a cabeça do fêmur na articulação do quadril do tamanduá bandeira, sendo o ponto de união entre os três ossos que constituem o osso do quadril. A borda do acetábulo era irregularmente espessa e descontínua devido à presença da incisura acetabular (Figura 1).

O forame obturado era o espaço circunscrito pelo púbis e ísquio, apresentou forma elipsoide, sendo sua designação dada em razão da existência de estruturas que ocluíam seu lúmen (Figura 1).

O fêmur do tamanduá bandeira formou o osso da coxa, constituído de corpo e duas extremidades. A extremidade proximal, ou epífise proximal, consistiu de cabeça, colo, trocânter maior e trocânter menor. A cabeça do fêmur formou uma proeminência arredondada mais extensa dorsal que ventralmente, dirigindo-se medialmente, com sua face articular voltada também medialmente, além de dorsalmente e ligeiramente caudal, articulando-se com o acetábulo (Figura 2). A cartilagem hialina cobre toda a face articular, exceto numa depressão central, a fóvea da cabeça do fêmur.

Observou-se nos animais estudados, que o colo do fêmur era o segmento ósseo que prendia a cabeça

FIGURA 2: Fotomacrografia do osso fêmur do tamanduá bandeira (Myrmecophaga tridactyla). (A), vista cranial; (B), vista caudal. CF, cabeça do fêmur; Cf, colo do fêmur; CF", corpo do fêmur; CL, côndilo lateral do fêmur; CM, côndilo medial do fêmur; EL, epicôndilo lateral do fêmur; EM, epicôndilo medial fêmur; FI, fossa intercondilar; ML, margem lateral do fêmur; TF, tróclea do fêmur; TM, trocânter maior; Tm, trocânter menor.
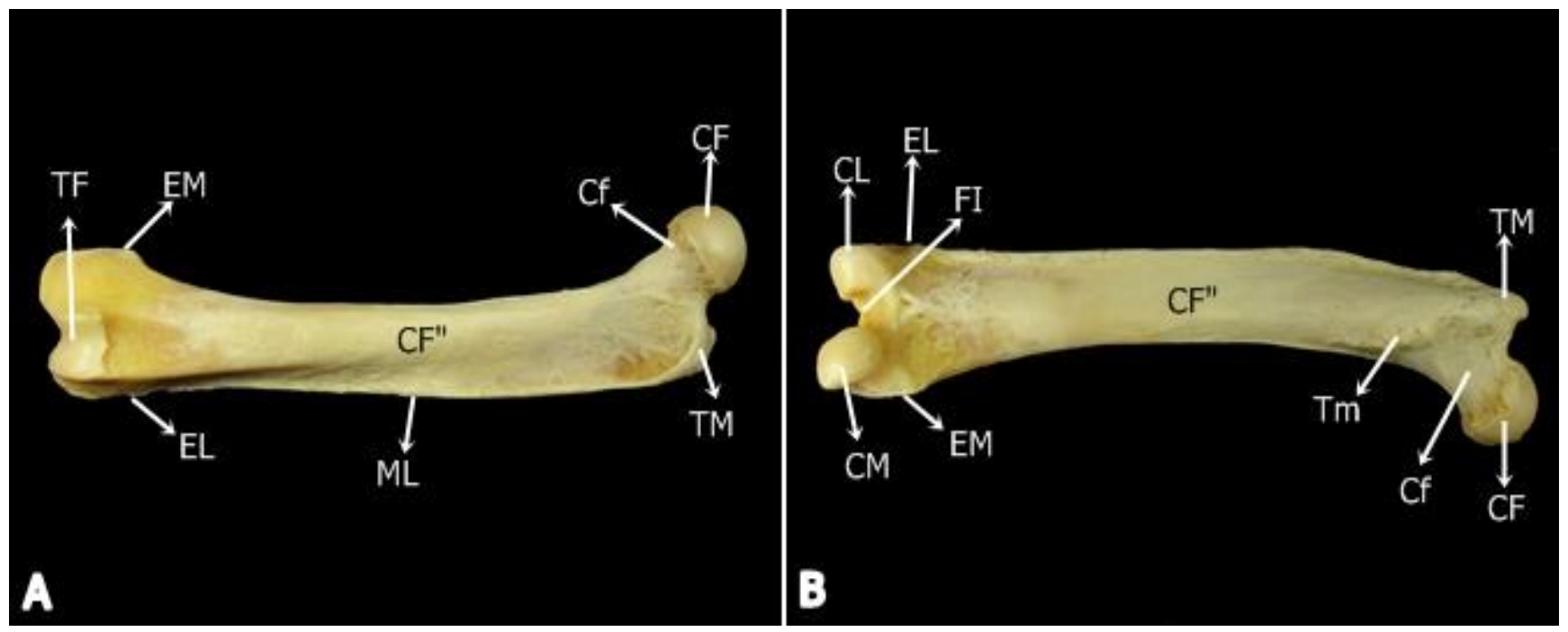
ao corpo. Seu limite com a cabeça era bem demarcado medial e lateralmente. O trocânter maior era uma protuberância óssea na face lateral que se projetou para cima. Sua borda livre era romba, rugosa e arqueada. Já o trocânter menor situou-se na face medial da extremidade proximal da diáfise do fêmur.

Quanto ao corpo do fêmur, este era cilíndrico, ligeiramente encurvado e apresentou em sua face lateral uma destacada margem, formando uma grande crista. A extremidade distal do fêmur revelou uma tróclea, que se situou na face cranial e articulou-se com a patela.

Ainda observando a extremidade distal do fêmur, notou-se a presença de dois côndilos, medial e lateral, com uma fossa intercondilar separando os dois côndilos. A superfície do côndilo medial era lisa e apresentou o epicôndilo medial, assim como observado na superfície do côndilo lateral com a presença do epicôndilo lateral, sendo o epicôndilo medial o mais proeminente (Figura 2).

A patela do tamanduá bandeira revelou forma aproximadamente triangular, com a base voltada para cima e o ápice voltado para baixo e inclinando-se lateralmente. Apresentou face cranial e duas superfícies articulares, medial e lateral, separadas por uma pequena elevação, na face caudal, que se articulou com a tróclea do fêmur (Figura 3).

Quanto à tíbia do tamanduá bandeira, esta era um pouco mais curta quando comparada ao fêmur. Sua extremidade proximal era larga e aproximadamente triangular, apresentando dois côndilos (medial e lateral), entre os quais se projetou a eminência intercondilar. Os côndilos da tíbia se articularam com os correspondentes côndilos do fêmur, sendo a face articular lateral convexa e a face medial suavemente plana. Seu ângulo cranial constituiu a tuberosidade da tíbia, que apresentou contorno triangular, sendo bastante larga e lisa. Esta se separou do côndilo lateral pelo sulco extensor.

O corpo da tíbia era inicialmente largo e de contorno triangular, tornando-se mais delgado e quadrangular nos terços médio e distal. Apresentou três faces: a face medial, larga e rugosa; a face lateral, lisa e ligeiramente retorcida; e a face caudal, plana e atravessada, obliquamente, por linhas musculares mais ou menos paralelas. Encontrou-se também três bordas: a borda cranial, proeminente no terço proximal do osso, terminando, gradativamente, em forma de linha; a borda medial, convexa longitudinalmente; e a borda lateral, que, na metade proximal do osso, era côncava e formou com a fíbula, o espaço interósseo da perna.

A extremidade distal da tíbia era menor que a

FIGURA 3: Fotomacrografia da patela do tamanduá bandeira (Myrmecophaga tridactyla). (A), vista cranial; (B), vista caudal. AP, ápice da patela; BP, base da patela; FC, face cranial da patela; SL, superfície lateral da face caudal da patela; SM, superfície medial da face caudal da patela.
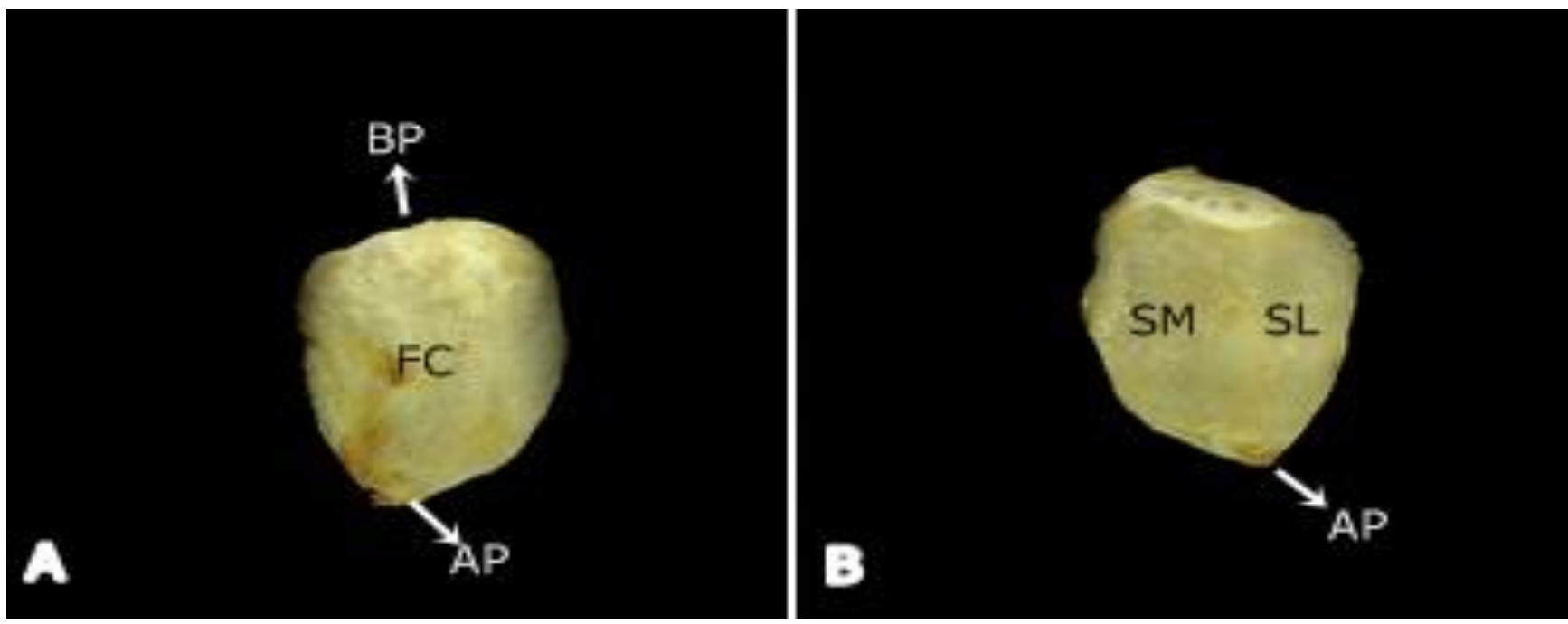
extremidade proximal, porém, mais larga que o corpo. Apresentou face articular para articulação com os ossos do tarso, sendo a superfície para articulação com o osso tálus denominada cóclea da tíbia. A epífise distal era formada por dois sulcos: um lateral, largo e pouco profundo; e um maleolar medial, mais profundo e estreito, sendo estes separados por uma crista. Medialmente o maléolo medial destacou-se como uma massa óssea (Figura 4).

A fíbula do Myrmecophaga tridactyla era o outro osso da perna e situou-se lateralmente à tíbia. Seu esboço era completo e constituiu um osso totalmente distinto da tíbia, sendo constituída por duas extremidades, a porção proximal, composta pela cabeça; e a porção distal, que se prolongou formando o maléolo lateral. Unindo essas porções destacou-se o corpo da fíbula. A cabeça estava articulada com o côndilo lateral da tíbia (Figura 4).

\section{Discussão}

Os ossos ílio, ísquio e púbis encontravam-se fundidos, uma vez que os animais estudados eram adultos. Oliveira (2001) apontou que dentre os gêneros
Tamandua, Cyclopes e Myrmecophaga, este último apresenta maior grau de fusionamento da articulação sacroilíaca. Para Varela (2010), a íntima união entre o apoio do membro pélvico e o tronco mediante a articulação sacroilíaca, que une firmemente o sacro ao cíngulo pélvico, garante uma transmissão eficaz do esforço propulsor.

O osso do quadril do tamanduá bandeira era semelhante ao dos carnívoros. Entretanto, algumas diferenças puderam ser evidenciadas como a presença de apenas uma incisura isquiática e a ausência da espinha isquiática no tamanduá, enquanto os carnívoros apresentam incisuras isquiáticas menor e maior e a espinha isquiática entre elas (GETTY, 1986b). Encontrou-se diferença também no formato do forame obturado, apresentado em forma de elipse no tamanduá bandeira e em forma de triângulo equilátero nos carnívoros (GETTY, 1986b).

Assim como a Agouti paca (OLIVEIRA et al., 2007) e a Dasyprocta azarae (OLIVEIRA et al., 2009) o Myrmecophaga tridactyla apresentou acetábulo arredondado e profundo, o que de acordo com os autores confere boa estabilidade coxo-femoral.

O tamanduá bandeira apresentou ainda, relativa

FIGURA 4: Fotomacrografia dos ossos tíbia e fíbula do tamanduá bandeira (Myrmecophaga tridactyla). (A), vista cranial; (B), vista caudal. BC, borda cranial da tíbia; BL, borda lateral da tíbia; BM, borda medial da tíbia; CF, cabeça da fíbula; Cf, corpo da fíbula; CL, côndilo lateral da tíbia; CM, côndilo medial da tíbia; CT, cóclea da tíbia; Ct, corpo da tíbia; EI, eminência intercondilar; FC, face caudal da tíbia; FL, face lateral da tíbia; FM, face medial da tíbia; ML, maléolo lateral; MM, maléolo medial; SE, sulco extensor; SL, sulco lateral; SM, sulco maleolar medial; TT, tuberosidade da tíbia.
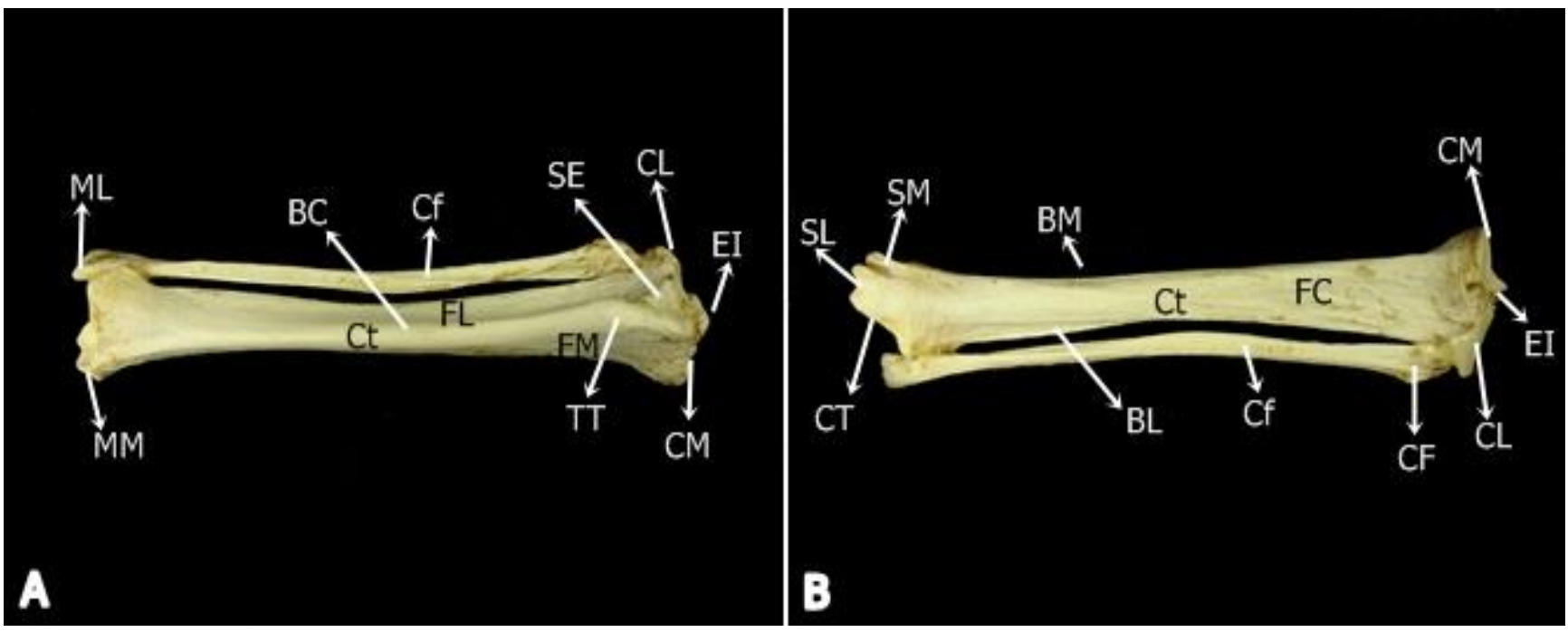
diminuição no comprimento do ílio e aumento do ísquio. Oliveira (2001) afirmou que a diminuição do comprimento do ílio favorece o fortalecimento desta região na cintura pélvica, por reduzir o torque produzido quando o peso do corpo é suportado pelo sacro, o que, de acordo com a autora, é uma tendência em animais de maior porte, como uma adaptação para redução do estresse decorrente do peso, destacando que as proporções relativas das regiões da cintura pélvica mudam de acordo com o estilo locomotor adotado, uma vez que nestas regiões originam-se músculos de grande importância à biomecânica da locomoção.

Oliveira (2001) afirma que a morfologia do fêmur dos mamíferos apresenta-se bastante variada, estando as modificações encontradas estritamente relacionadas com aspectos adaptativos dos animais a diferentes estilos de vida. O tamanduá bandeira apresentou trocânter menor pouco destacado, assim como a Agouti paca (OLIVEIRA et al., 2007) e a Dasyprocta azarae (OLIVEIRA et al., 2009); e ausência de fossa trocantérica, diferente do que ocorre nos carnívoros, em que o trocânter menor tem o formato de uma tuberosidade rombuda e a fossa trocantérica é redonda e profunda (GETTY, 1986b). A crista apresentada na margem lateral do corpo do fêmur, de acordo com Oliveira (2001) corresponde a uma pequena expansão áspera e representa um vestígio do terceiro trocânter, no tamanduá bandeira esta crista apresentou-se bastante destacada.

Como osso sesamoide, a patela atua como polia móvel que anterioriza a ação do músculo quadríceps femoral, tornando-a mais eficaz (DÂNGELO; FATTINI, 2007). Visto a pequena dimensão da patela no tamanduá bandeira, relativamente ao seu porte, infere-se que seja pequena a potencialização do referido músculo, causada por esse osso. A face caudal, que se articula com o fêmur, é bastante pronunciada, possivelmente para evitar o deslocamento patelar, que pode ocorrer em virtude da postura quadrúpede terrestre (OLIVEIRA, 2001).

A morfologia da tíbia e fíbula do tamanduá bandeira era semelhante a dos carnívoros, entretanto, nesses últimos a parte distal da fíbula era achatada e encontrava-se intimamente ligada à tíbia (GETTY, 1986b). Em Agouti paca (OLIVEIRA et al., 2007) a tíbia e a fíbula se equivaleram em comprimento e eram parcialmente fundidas por uma fibrocartilagem em suas extremidades; enquanto no tamanduá bandeira, bem como em Dasyprocta azarae (OLIVEIRA et al., 2009), os dois ossos também se equivaleram em comprimento, mas não houve fusão entre eles em nenhum ponto.

Assim como o fêmur, a morfologia da tíbia e fíbula refletem padrões relacionados ao estilo locomotor adotado pelo animal. A espécie estudada apresentou a tíbia mais curta que o fêmur, enquanto os carnívoros apresentavam os dois ossos com praticamente o mesmo comprimento (GETTY, 1986b). Segundo Oliveira (2001), a importância de um fêmur maior que a tíbia está relacionada com o fato de que segmentos distais mais curtos resultam em movimentos mais poderosos.

A partir dos resultados, foi possível concluir que o esqueleto do cíngulo pélvico do tamanduá bandeira era constituído pelo osso do quadril, formado pelos ossos ílio, púbis e ísquio; a coxa era constituída pelo osso fêmur; e a perna pelos ossos tíbia e fíbula. Na região da articulação do joelho encontrava-se a patela, um osso sesamoide relativamente pequeno, considerandose o grande porte do animal. Os tamanduás bandeira apresentaram características osteológicas do cíngulo pélvico, coxa e perna semelhantes àquelas dos carnívoros domésticos, com os quais foram relacionados por uma maior proximidade em relação ao porte e quantidade de dedos. Entretanto, algumas diferenças morfológicas foram evidenciadas, como a presença de apenas uma incisura isquiática, a ausência da espinha isquiática, forame obturado em forma de elipse, trocânter menor pouco destacado, ausência de fossa trocantérica, destacada crista na margem lateral do fêmur e ausência de fusão entre a tíbia e a fíbula, o que pode refletir as diferenças dos padrões locomotores.

\section{Agradecimentos}

Nossos agradecimentos a Lucélia Gonçalves Vieira por sua contribuição na ilustração do trabalho. 


\section{Referências}

COlleVATtI, R. G.; LEITE, K. C. E.; MIRANDA, G. H. B.; RODRIGUES, F. H. G. Evidence of high inbreeding in a population of the endangered giant anteater, Myrmecophaga tridactyla (Myrmecophagidae), from Emas National Park, Brazil. Genetics and Molecular Biology, Ribeirão Preto, v. 30, n. 1, p. 112-120, 2007.

DÂNGELO, J. G.; FATTINI, C. A. Anatomia humana, sistêmica e segmentar. 3. ed. São Paulo: Atheneu, 2007. 763 p.

GETTY, R. Anatomia dos animais domésticos. Vol. 1. 5. ed. Rio de Janeiro: Interamericana, 1986a. 1134 p.

GETTY, R. Anatomia dos animais domésticos. Vol. 2. 5. ed. Rio de Janeiro: Interamericana, 1986b. 580 p.

INTERNATIONAL COMMITTEE ON VETERINARY GROSS ANATOMICAL NOMENCLATURE. Nomina anatomica veterinária. 5. ed. (rev.) Knoxville: World Association on Veterinary Anatomist, 2012. 177 p.

MARTÍNEZ, J. A. G. Importancia y aplicación del dibujo científico em osteología e entomología. 2007. 162 f. Tesina (Licenciatura en Biología) - Universidad Autónoma Del Estado de Hidalgo, Pachuca de Soto. 2007.

MEDRI, I. M.; MOURÃO, G. Home range of giant anteaters (Myrmecophaga tridactyla) in the Pantanal wetland, Brazil. Journal of Zoology, Londres, v. 266, p. 365-375, 2005.
MEDRI, I. M.; MOURÃO, G. M.; RODRIGUES, F. H. G. Ordem Pilosa. In: REIS, N. R.; PERACCHI, A. L.; PEDRO, W. A.; LIMA, I. P. (Ed.). Mamíferos do Brasil. 2 ed. Londrina, Nélio R. Reis, 2011. p. 91-106.

OLIVEIRA, F. S.; CANOLA, J. C.; MACHADO, M. R. F; CAMARGO, M. H. B. Descrição anátomo-radiográfica do esqueleto apendicular da paca (Agouti paca). Acta Scientiae Veterinariae, Porto Alegre, v. 35, n. 1, p. 83-87, 2007.

OLIVEIRA, F. S.; MARTINS, L. L.; PAULONI, A. P.; TONIOLLO, G. H.; CANOLA, J. C.; MACHADO, M. R. F. Descrição anátomoradiográfica do esqueleto apendicular da cutia (Dasyprocta azarae, Lichtenstein, 1823). ARS Veterinária, Jaboticabal, v. 25, n. 1, p. 28-31, 2009.

OLIVEIRA, M. F. Morfologia funcional e desenho corporal da cintura pélvica e membros posteriores dos tamanduás (Mammalia: Xenarthra: Myrmecophagidae). 2001. $90 \mathrm{f}$. Dissertação (Mestrado em Ciências Biológicas) - Universidade Federal do Pará, Belém. 2001.

RODRIGUES, H. Técnicas anatômicas. 3. ed. Vitória: GM Gráfica e Editora, 2005. 229 p.

SILVEIRA, M. J.; OLIVEIRA, E. F. A importância das coleções osteológicas para o estudo da biodiversidade. Revista Saúde e Biologia, Campo Mourão, v. 3, n. 1 p.1-4, 2008.

VARELA, G. Osteología y miología de lós miembros anterior e posterior del venado de campo (Ozotoceros bezoarticus). 2010. 51 f. Tesina (Licenciatura en Ciencias Biológicas) - Universidad de La República Uruguay, Montevideo. 2010. 